\title{
Review of Type 2 Diabetes Mellitus Treatment and Relation with Hemoglobin A1c in Diabetes Center- Dr. Sulaiman Al Habib Hospital, Dubai, UAE
}

\author{
Omar Dhaimat*, Maryam Edraki, Ghaida Kaddaha, Jaber Al Ansari and Nur Ahmed \\ Dubai Health Care City- United Arab Emirates (UAE) \\ *Corresponding author: Omar Dhaimat, Diabetes Center, Dr. Sulaiman AL Habib Hospital, Dubai Health Care City- United \\ Arab Emirates (UAE)
}

\begin{abstract}
ARTICLE INFO
Received: 慧 August 03, 2019

Published: 慧 September 11, 2019

Citation: Omar Dhaimat, Maryam Edraki, Ghaida Kaddaha, Jaber Al Ansari, Nur Ahmed. Review of Type 2 Diabetes Mellitus Treatment and Relation with Hemoglobin A1c in Diabetes Center- Dr. Sulaiman Al Habib Hospital, Dubai, UAE. Biomed J Sci \& Tech Res 21(2)-2019. BJSTR. MS.ID.003578.
\end{abstract}

Keywords: Type 2 diabetes mellitus; T2DM, HbA1c<7; ADA; Dubai; Monotherapy; Dual Therapy; Oral Antihyperglycemic Agents; Insulin; GLP-1

\section{ABSTRACT}

Objective: To determine the percentage of patients with type 2 diabetes mellitus (T2DM) in a Diabetes Center in UAE, with glycated hemoglobin level (HbA1c) recommended by American Diabetes Association (ADA), i.e., HbA1c $<7$, and the class of antidiabetic drugs received by them.

Methods: A retrospective study was conducted at Diabetes Center in May 2018 in patients who had T2DM with complete information related to HbA1c. The primary endpoint of the study was to determine the percentage of patients with T2DM and $\mathrm{HbA1c}<7 \%$, while the secondary endpoint was to review the distribution of the various classes of anti-diabetic agents used to attain the HbA1c level of $<7 \%$. The data collected were analyzed descriptively and were presented as n (\%) and mean (standard deviation; SD).

Result: Out of 270 patients, nine $(n=9 ; 3.3 \%)$ patients had gestational diabetes, $13(4.8 \%)$ patients had type $1 \mathrm{DM}$ and only $248(91.9 \%)$ patients were identified with T2DM. Among 248 patients with T2DM, the quarterly HbA1c information was available for $234(94.4 \%)$ patients. One hundred twenty-five $(n=125 ; 53.4 \%)$ patients with T2DM had $\mathrm{HbA} 1 \mathrm{c}<7 \%$, out of which $86(68.8 \%)$ patients received only oral antihyperglycemic agents (OHAs; mean [SD]: HbA1c=6.2 [0.33]), one $(0.8 \%)$ patient received only insulin (HbA1c=6), three $(n=3,2.4 \%)$ patients received only glucagon-like peptide-1 (GLP-1) agonists (mean [SD] HbA1c=5.7 [0.35]), 8 (6.4\%) patients received insulin+OHAs (mean [SD] HbA1c=6.4 [0.29]), 23 (18.4\%) patients took GLP-1+OHAs (mean [SD] HbA1c=6.3 $[0.38])$ and one $(0.8 \%)$ patient received GLP-1+OHA+insulin $(\mathrm{HbA1}=6)$. Three $(\mathrm{n}=3$, $2.4 \%$ ) were newly diagnosed prediabetic patients who received no drug (mean [SD] HbA1c $=6.1$ [0.38]). Patients received monotherapy $(n=66 ; 52.8 \%)$, dual therapy $(n=39$; $31.2 \%)$ and more than two drugs $(n=20,16.0 \%)$. Among monotherapy, metformin was the most frequently received drug $(n=40 ; 32.0 \%)$ while metformin+GLP-1 was most commonly received dual therapy $(n=11 ; 8.8 \%)$.

Conclusion: Glycemic control of HbA1c $<7$ was achieved by $53.4 \%$ patients, which is much higher proportion of patients than previously reported from this region; however, it was still below the target level in many patients.

\section{Introduction}

Diabetes Mellitus (DM), a global epidemic, has become one of the major health related challenges and estimated to be the seventh leading cause of mortality in 2016 [1]. The global prevalence of DM in adults aged between 20-79 years was approximately 425 million in 2017[2]. Prevalence of Type 2 DM (T2DM) is increasing and has become a global pandemic affecting developed as well as developing countries of the world [3]. As per International Diabetes Federation (IDF), $17.3 \%$ of the United Arab Emirates (UAE) aged between 2079 years had T2DM in 2017 [4]. According to a systematic review published by Meo (2016), the prevalence of T2DM has increased in 
Saudi Arabia from 2.5\% in the year 1982 to $32.8 \%$ in the year 2015 [5]. Therefore, a prompt, accurate and early diagnosis as well as an appropriate treatment is warranted.

Glycated/ glycosylated hemoglobin, also known as hemoglobin A1c (HbA1c), plays an essential role in diagnosing and monitoring T2DM [6]. American Diabetes Association (ADA), 2018 recommends targeting $\mathrm{HbA} 1 \mathrm{c}$ level of less than $7 \%(<7)$ [7]. This has been supported by numerous landmark trials that report the association between $\mathrm{HbA} 1 \mathrm{c}<7 \%$ and reduced risk of microvascular complications. Veterans Affairs Diabetes Trial [VADT]) assessing glucose control and vascular complications in 1791 veterans with T2DM reported median HbA1c of $6.9 \%$ in the group receiving intensive therapy and $8.4 \%$ in the group receiving standard therapy. Furthermore, the first major cardiovascular event was experienced by lesser number of patients with lower HbA1c than patients with higher HbA1c (235 vs. 264; p=0.14) [8]. Action in Diabetes and Vascular Disease: Preterax and Diamicron Modified Release Controlled Evaluation (ADVANCE) trial also reported a $10.0 \%$ relative reduction in major macrovascular and microvascular events in patients with T2DM with $\mathrm{HbA1c}=6.5 \%$ [9]. The Other landmark studies including Kumamoto Study [10] and UK Prospective Diabetes Study (UKPDS) also confirmed that intensive glycemic control (HbA1c=7.0 for UKPDS and 7.1 for Kumamoto study) significantly reduced microvascular complication rates in patients with T2DM. $[11,12]$.

A 10 year follow up of UKPD seven revealed the long-term benefit of intensive glycemic control in patients with T2DM [13]. Though, numerous studies assessed the prevalence of T2DM in Middle East region, [14-16] very few studies report the prevalence of T2DM based on HbA1c levels. Therefore, the present retrospective study was conducted to determine the percentage of patients with HbA1c $<7 \%$ with T2DM in Diabetes Center- Dr. Sulaiman AL Habib Hospital as recommended by ADA. The study also reviewed the

\section{Primary End Point}

distribution of the various classes of anti-diabetic agents used to attain this level of HbA1c.

\section{Methodology}

\section{Study Design}

A retrospective study was conducted at Diabetes Center, Dr. Sulaiman AL Habib Hospital in May 2018 to determine the number/ percentage of patients with $\mathrm{T} 2 \mathrm{DM}$ and $\mathrm{HbA} 1 \mathrm{c}<7 \%$ and the class of antidiabetic drugs received by them.

\section{Study Population}

The patients with T2DM, and complete information related to HbA1c were included in the study while the patients with incomplete information and/ or other type of DM were excluded.

\section{Study Endpoints}

The primary endpoint of the study was to determine the percentage of patients with T2DM and $\mathrm{HbA} 1 \mathrm{c}<7 \%$. The secondary endpoint was to review the distribution of the various classes of anti-diabetic agents used to attain the HbA1c level of $<7 \%$.

\section{Statistical Analysis}

The data collected were analyzed descriptively and were presented as $\mathrm{n}(\%)$ and mean (standard deviation; SD).

\section{Result}

\section{Study Population}

A total of 1089 patients attended the Center in May, 2018 out of which 270 had DM. Among them, nine (n=9; 3.3\%) patients had gestational diabetes, 13 (4.8\%) patients had type $1 \mathrm{DM}$ and only 248 (91.9\%) patients were identified with T2DM. Among 248 patients with T2DM, the quarterly HbA1c information was missing for $14(5.7 \%)$ patients. Therefore, data of only 234 (94.4\%) patients was analyzed further.

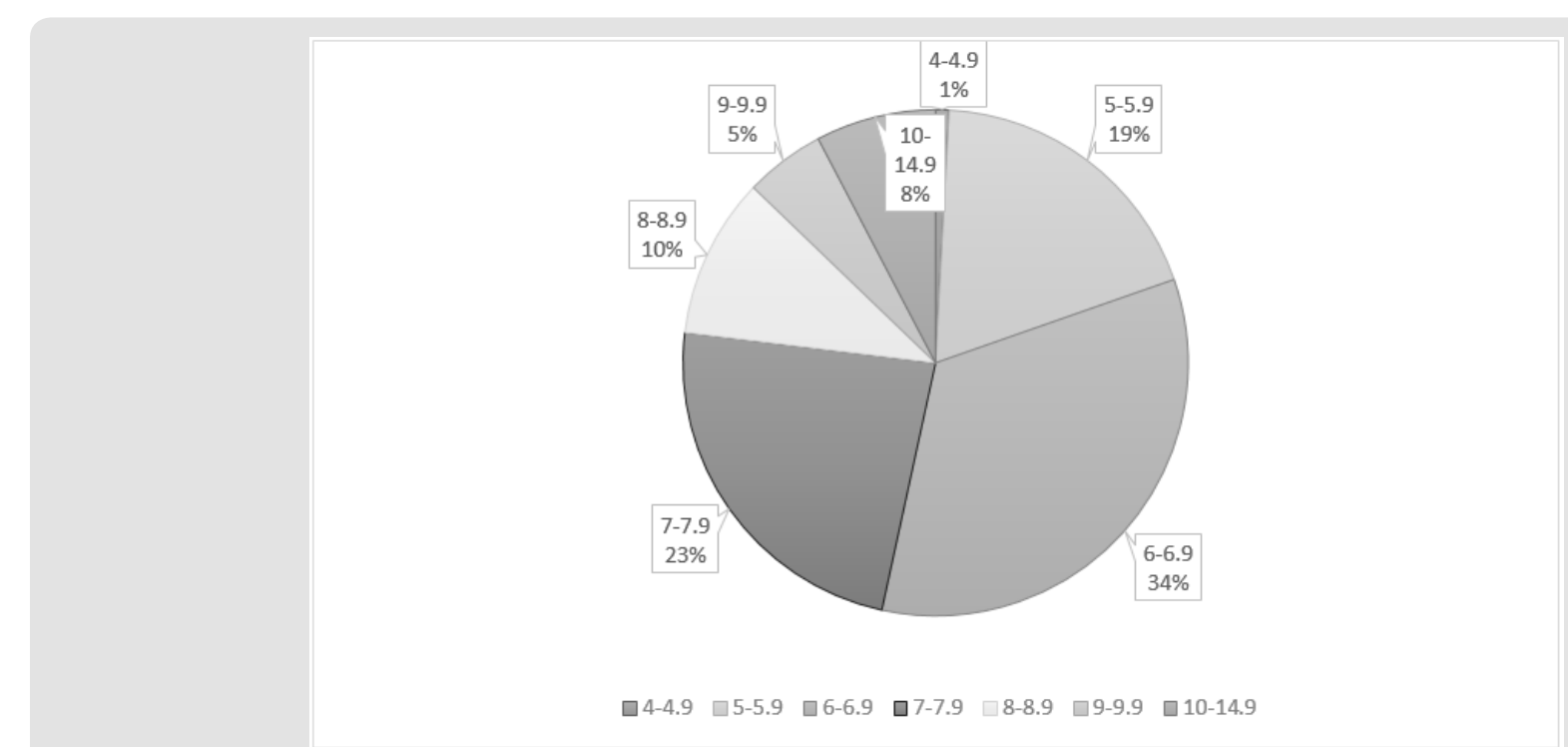

Figure 1: Distribution of patients in different $\mathrm{HbA1c}$ ranges. 
Among 234 patients with T2DM, 109 (46.6\%) patients had HbA1c>7\% while 125 (53.4\%) patients had HbA1c<7\%. Among patients with $\mathrm{HbA1}<<7(\mathrm{n}=125)$, the highest number of patients, i.e., $79(63.2 \%)$ patients had HbA1c within the range of $6.0-6.9 \%$, followed by $44(35.2 \%)$ patients in $5.0-5.9 \%$ and only two $(n=2$; $1.6 \%$ ) patients with $\mathrm{HbA} 1 \mathrm{c}$ between $4.0-4.9 \%$. Out of 109 patients with $\mathrm{HbA} 1 \mathrm{c}>7,55(50.5 \%)$ patients had $\mathrm{HbA1c}$ within a range of 7.0-7.9\%, 24 (22.0\%) patients in 8.0-8.9, 12 (11.0\%) in 9.0-9.9 and $18(16.5 \%)$ in $10-14.9 \%$. Overall, the HbA1c ranges and distribution of patients is presented in Figure 1.

\section{Secondary End Point}

Of the T2DM patients with $\mathrm{HbA1c}<7,86$ (68.8\%) patients received only oral antihyperglycemic agents (OHAs), one $(0.8 \%)$ patient received only insulin, and three $(n=3,2.4 \%)$ patients received only glucagon-like peptide-1 (GLP-1) agonists. A combination of

Table 1: Antihyperglycemic agents received by patients with type 2 diabetes mellitus and mean $\mathrm{HbA1c}<7$.

\begin{tabular}{|c|c|c|c|}
\hline Antihyperglycemic Agents & Number of Patients & Percentage of Patients (\%) & Mean (SD) and/or Actual HbA1c (\%) \\
\hline \multicolumn{4}{|c|}{ Monotherapy } \\
\hline Metformin & 40 & 32 & $5.9(0.56)$ \\
\hline SU & 1 & 0.8 & $6.5(0.0)$ \\
\hline GLP-1 & 3 & 2.4 & $5.7(0.35)$ \\
\hline DPP4 & 18 & 14.4 & $6.0(0.46)$ \\
\hline SGLT2 & 4 & 3.2 & $5.8(0.76)$ \\
\hline \multicolumn{4}{|c|}{ Dual therapy } \\
\hline Metformin + GLP1 & 11 & 8.8 & $6.2(0.62)$ \\
\hline Metformin+ DDP4 & 4 & 3.2 & $6.3(0.64)$ \\
\hline Metformin+ SGLT2 & 3 & 2.4 & $5.7(0.62)$ \\
\hline Metformin+ LABA & 2 & 1.6 & $6.4(0.35)$ \\
\hline Metformin+ premixed insulin & 1 & 0.8 & $6.0(0.0)$ \\
\hline TZD+DPP4 & 1 & 0.8 & $6.6(0.0)$ \\
\hline SU+DPP4 & 3 & 2.4 & $6.3(0.56)$ \\
\hline GLP1+SGLT2 & 2 & 1.6 & $6.6(0.50)$ \\
\hline DPP4+LABA & 1 & 0.8 & $6.8(0.0)$ \\
\hline DPP4+SGLT2 & 10 & 8 & $6.2(0.50)$ \\
\hline RAIA+LABA & 1 & 0.8 & $6.0(0.0)$ \\
\hline \multicolumn{4}{|c|}{ Combinations with three or more than three drugs } \\
\hline Metformin+SU+GLP1+DPP4 & 1 & 0.8 & $6.9(0.0)$ \\
\hline Metformin+SU+GLP1 & 3 & 2.4 & $6.4(0.3)$ \\
\hline Metformin+GLP1+SGLT2 & 2 & 1.6 & $6.0(0.85)$ \\
\hline Metformin+ DPP4+RAIA+LABA & 1 & 0.8 & $6.6(0.0)$ \\
\hline Metformin+RAIA+LABA & 1 & 0.8 & $6.1(0.0)$ \\
\hline SU+TZD+DPP4+SGLT2 & 1 & 0.8 & $6.0(0.0)$ \\
\hline TZD+GLP1+DPP4 & 1 & 0.8 & $5.8(0.0)$ \\
\hline SU+GLP1+SGLT2 & 1 & 0.8 & $6.3(0.0)$ \\
\hline SU+GLP1+SGLT2+LABA & 1 & 0.8 & $6.5(0.0)$ \\
\hline SU+SGLT2+LABA & 1 & 0.8 & $6.3(0.0)$ \\
\hline SU+GLP1+DPP4+SGLT2 & 1 & 0.8 & $5.7(0.0)$ \\
\hline GLINIDE+DPP4+SGLT2 & 1 & 0.8 & $6.7(0.0)$ \\
\hline
\end{tabular}

insulin+OHAs was received by $8(6.4 \%)$ patients and $23(18.4 \%)$ patients took GLP-1+OHAs combination. Three $(n=3,2.4 \%)$ newly diagnosed prediabetic patients (mean HbA1c 6.13 [0.38]) had received no drug at data cut off and were planned to be managed with lifestyle modification interventions (Table 1) [17].

Overall, patients received monotherapy ( $n=66 ; 52.8 \%)$, dual therapy $(n=39 ; 31.2 \%)$ and more than two drugs $(n=20,16.0 \%)$. Among monotherapy, metformin alone was the most frequently received drug $(n=40 ; 32.0 \%$ of total patients) followed by DPP4 which was received by 18 (14.4\% of total patients) patients (Table 1). Among dual therapy, the combination of metformin and GLP1 was most commonly received by 11 ( $8.8 \%$ of total patients) patients followed by the combination of dipeptidyl peptidase- 4 (DPP4) inhibitors and sodium-glucose co-transporter-2 (SGLT2) inhibitors $(n=10,8.0 \%)$. All the other dual therapy and other multiple combinations were less common and are listed in Table 1. 


\begin{tabular}{|c|c|c|c|}
\hline GLP1+SGLT2+LABA & 1 & 0.8 & $6.6(0.0)$ \\
\hline DPP4+SGLT2+LABA & 1 & 0.8 & $6.6(0.0)$ \\
\hline No Drug & 3 & 2.4 & $6.1(0.38)$ \\
\hline
\end{tabular}

DPP4: Dipeptidyl peptidase-4; SGLT2: Sodium-glucose co-transporter-2; GLP1: Glucagon-like peptide-1; PGR: Prandial glucose regulator; SU: Sulphonylureas; LABA: Long acting basal analogue; RAIA: Rapid acting insulin analog; TZD: Thiazolidinedione; SD: Standard deviation

\section{HbA1c levels of Each Group}

The patients taking only OHAs had a mean (SD) HbA1c of 6.2 (0.33), while the only patient on insulin had HbA1c level of $6 \%$. The patients receiving the combination of insulin+OHA had mean (SD) HbA1c=6.4 (0.29). The patients receiving only GLP-1 had a mean HbA1c= 5.7 (0.35) while those on GLP-1 in combination with insulin and $\mathrm{OHAs}$, the $\mathrm{HbA1c}$ level was 6.6. HbA1c levels of patients on various drug combinations are listed in Table 2.

Table 2: Class of antihyperglycemic agents received by patients with type 2 diabetes mellitus and mean $\mathrm{HbA} 1 \mathrm{c}<7$.

\begin{tabular}{|c|c|c|}
\hline Class & N (\%) & $\begin{array}{c}\text { Mean (SD) and/or } \\
\text { Actual HbA1c (\%) }\end{array}$ \\
\hline OHAs & $86(68.8)$ & $6.2(0.33)$ \\
\hline GLP-1 & $3(2.4)$ & $5.7(0.35)$ \\
\hline GLP-1 +OHAs & $23(18.4)$ & $6.3(0.38)$ \\
\hline Insulin & $1(0.8)$ & $6.0(0.0)$ \\
\hline Insulin +OHAs & $8(6.4)$ & $6.4(0.29)$ \\
\hline Insulin +GLP-1+ OHA & $1(0.8)$ & $6.6(0.0)$ \\
\hline No drug & $3(2.4)$ & $6.1(0.38)$ \\
\hline
\end{tabular}

OHAs: Oral antihyperglycemic agents; GLP: Glucagon-like peptide; SD: Standard deviation

\section{Discussion}

There is a high prevalence of T2DM in UAE [18-22]. which needs to be managed by maintaining glycemic levels as normal as nondiabetic range $[23,24]$. To monitor the glycemic levels, HbA1C test is considered as the standard of care for diagnosing and monitoring T2DM. It is a reliable test and is widely accepted as it provides an average of blood glucose levels in the past two to three months [25].

The guidance by ADA recommends targeting HbA1c $<7 \% .7$ However, as per guidance statement update from the American College of Physicians (ACP), an HbA1c level between 7 and $8 \%$ should be aimed by the clinicians in most of the patients with T2DM. In patients with HbA1c $<6.5 \%$, de-intensifying pharmacologic therapy should be recommended [26]. Though ADA and ACP guidance agree in various areas, ADA does not consider ACP guidance of standard glycemic control (HbA1c: 7-8) appropriate as long term data from studies have shown intensive glycemic control $(\mathrm{HbA} 1 \mathrm{c}<7)$ is associated with reduced glycemic complications [8-10,27]. Literature also suggests that intensive glycemic control in patients with T2DM has long term benefit in reducing cardiovascular complications [13].
Keeping in consideration the benefits associated with lower HbA1c levels $(<7)$, the present study also assessed the percentage of patients with T2DM, in a hospital at Dubai Health Care City, who achieved $\mathrm{HbA} 1 \mathrm{c}$ target of $<7 \%$ as primary endpoint. If ACP was being followed, the present study had 88 patients would have required de-intensifying treatment as their HbA1c levels were $<6.5 \%$.

Diabetes accounts for high economic burden in Middle East region. AlMazroa determined the cost of DM in Saudi Arabia and estimated the cost to be 17 billion Riyals which is expected to rise up to 43 billion Riyals in future if the glucose intolerance progresses at the current observed rate [28]. Such a financial strain warrants immediate attention [29] and this could be achieved by diagnosing early and preventing complications associated with T2DM.

Limited studies conducted in Middle East region have assessed the prevalence of T2DM based on ADA HbA1c targets (HbA1c: $<7 \%$ ) and they consistently report a failure in targeting as well as meeting ADA standards in most of the patients with T2DM. A cross-sectional, population-based survey in 2006 reported the prevalence of T2DM with $\mathrm{HbA} 1 \mathrm{c}<7$ as $16.7 \%$ in Syria in a random sample of 1168 subjects $\geq 25$ years of age [30]. Another study determining the prevalence of DM and its complications in 2455 adults (>18 years) in Al Ain, UAE reported $10.2 \%$ population had DM, out of which only $33.3 \%$ achieved HbA1c targets of less than 7\% [31]. Among 353 Saudi T2DM patients, the average last measured $\mathrm{HbA1c}$ was $8.2 \pm 1.89 \%$ out of which only $27 \%$ achieved the target of $\mathrm{HbA} 1 \mathrm{c}<7 \%$. However, as per physicians $42 \%$ of the patients had attained glycemic control [32]. A study conducted in Riyadh, Saudi Arabia reported that ADA target for HbA1c was only met in $21.8 \%$ of 968 patients [33]. Another study conducted in Saudi Arabia, Asser region, reported $26 \%$ of total $(n=637)$ to have poor glycemic control [34].

Similarly, Alramadan et al. [35] reported three fourth of the total 1111 participants attending diabetes centers in Riyadh, Hofuf and Jeddah cities with unmet ADA glycemic targets [35]. This shows that the knowledge of ADA HbA1c target of $<7$ was probably not well known to the physicians. In contrast to the above-mentioned studies, the present study reported a higher percentage of patients with $\mathrm{HbA1c}<7$, i.e., $53.4 \%(\mathrm{n}=125)$. This is due to comprehensive diabetes care services provided by our Center inclusive of early and accurate diagnosis, with appropriate treatment strategies and follow-up. Our strategy is supported by a study conducted from Dubai which showed that a diabetes care programme led to 
an increase in proportion of patients achieving $\mathrm{Hba1c}<7 \%$ from $20.6 \%$ to $31.7 \%$ [36].

Antihyperglycemic therapy plays an essential role in attaining normoglycemia in patients with T2DM. However, it is important to select the appropriate therapy amongst the available agents for its management [37]. Generally, the patients recently diagnosed with T2DM are prescribed with metformin monotherapy with lifestyle modifications. However, in case of failure to attain normoglycemia, the patients are recommended combination therapy, i.e., dual followed by triple followed by insulin alone or in combination with OHAs [38,39].

Al Elq et al. [32] reported the use of OHAs alone in 64\%, followed by combination of OHAs and insulin (28\%) and insulin alone in $7 \%$ patients with T2DM $(n=353)$ [32]. In this study, the average last measured $\mathrm{HbA} 1 \mathrm{c}$ was $8.2 \pm 1.89 \%$. Only $27 \%$ of patient population had reached the target $\mathrm{HbA} 1 \mathrm{c}$ of $<7 \%$. Despite this, the physicians had considered that $42 \%$ of patients had reached glycemic control [32]. Considering the same drug/drug combinations as the study by Al-Elq et al. [32] OHAs were also most commonly used by 86 $(68.8 \%)$ patients in the present study, followed by combination of OHAs and insulin $(n=8,6.4 \%)$ and then insulin alone $(n=1,0.8 \%)$. However, the average (SD) HbA1c in these patient groups were 6.18 (0.33) for the patients receiving OHAs, $6.0(0.0)$ for insulin and 6.39 $(0.29)$ for the patients receiving insulin+OHAs.

In contrast to the study by Al-Elq et al. in the present study, $53.4 \%$ of study population reached the target $\mathrm{HbA} 1 \mathrm{c}$ of $<7 \%$. A systematic review of 218 randomized controlled trials including 78,945 patients determined the proportion of patients with T2DM targeting HBA1c $<7$ using antidiabetic drugs. The study reported that patients took insulin in basal $(n=21615)$, biphasic $(n=11921)$, prandial $(n=2597)$, basal bolus $(n=2967)$ form and targeted HbA1c $<7$ was achieved by $38.9,34.4,36.3$, and $50.2 \%$ of patients, respectively [39]. Of the patients receiving GLP 1 agonists $(n=5783)$, $45.7 \%$ attained the HbA1c target of $<7$.

Among OHAs, $39.0 \%$ of 13,847 patients receiving DPP4 inhibitors, $25.9 \%$ of 1120 patients receiving alpha glucosidase inhibitors, $33.2 \%$ of 6655 patients receiving thiazolidinediones, $48.2 \%$ of 5895 patients receiving sulphonylureas, $39.1 \%$ of 1050 patients receiving glinides and $42.0 \%$ of 4827 patients receiving metformin attained the HbA1c target of $<7.39$ Though the present study population was small, patients received all the drugs reported for T2DM in the study by Esposito et al., 2012 except alpha-glucosidase inhibitors. In the present study, a total of $51.8 \%$ patients receiving DPP4 inhibitors, 9.1\% patients receiving thiazolidinediones, $33.3 \%$ patients receiving sulphonylureas, $33.3 \%$ patients receiving glinides and $74.7 \%$ patients receiving metformin attained the HbA1c target of $<7$. Of the patients with HbA1c $<7$ in the present study, only one patient was on only insulin (rapid acting and long acting basal) and had HbA1c of $6 \%$. The combination of insulin and OHAs was used in $8(6.4 \%)$ patients with HbA1c $<7$ and mean HbA1c (SD) was 6.39 (0.29).

Blonde et al. [40] reported $41.1 \%$ patients taking GLP-1 agonists attained $\mathrm{HbA} 1 \mathrm{C}<7 \%$ in patients [40]. In the present study, of the patients taking GLP-1 agonists, $58.7 \%$ attained the HbA1c target of $<7$. GLP1 was used alone $(n=1,0.8 \%)$ and in combination with OHAs $(n=23,18.4 \%)$ in these patients who attained the HbA1c target of $<7$.

Metformin is also received in conjunction with insulin and numerous studies support the combined use of insulin and metformin. Ponssen et al. [41] included 30 patients with T2DM and reported the combination to improve glycemic levels, decrease adverse events with reduced insulin requirement [41]. Another study also reported the same in 2002 [42]. A 1998 study by Hermann reported metformin+insulin as a better combination than insulin+sulphonylureas in obese patients with T2DM [43]. In concordance, a combination of metformin and insulin was received by three (2.4\%) patients (mean [SD] HbA1c: 6.23 [0.32]) and none of the patients in the present study received a combination of insulin and sulphonylureas. In the present study, combination of metformin and GLP-1 agonist combination was received by 13 patients out of which $8.8 \%(n=11)$ patients attained $\mathrm{HbA1}<<$, while only $3.2 \%(n=4)$ out of six patients receiving a combination of metformin and DPP4 inhibitors attained HbA1c $<7$. Pratley et al. 2010 also supports the combination of metformin and GLP-1 agonists over the combination of metformin and DPP4 inhibitors in achieving HbA1c target (baseline HbA1c: 8.5\%; n=665, HbA1c lowering by $1.8 \mathrm{mg}$ liraglutide [GLP-1 agonist]: $-1.5 \%$; $=218,1.2$ mg liraglutide [GLP-1 agonist]: $-1.2 \% ; n=221,100 \mathrm{mg}$ sitagliptin [DPP4 inhibitor]: -0.9\%; $n=219$ ) [44].

A meta-analysis conducted to compare SGLT2 inhibitor+DPP4 inhibitor with placebo+DPP4 inhibitor in patients with T2DM reported better glycemic control in the group receiving SGLT2 inhibitor+DPP4 inhibitor (weighted mean difference $-0.6 \%, 95 \%$ CI -0.7 to $-0.5 \%$ ) [45]. The present study also revealed that 10 $(8.0 \%)$ out of 14 patients receiving the same combination attained HbA1c $<7$ (mean [SD] HbA1c: 6.19 [0.50]).

The patients who do not attain target $\mathrm{HbA1c}$ values with dual therapy are recommended more than two drugs. However, it is essential to be careful while choosing such a treatment regime due to the associated risk of hypoglycaemia. Moreover, very few studies report the long -term efficacy and safety of such combinations [46]. Furthermore, polypharmacy is associated with increased risks of patient non-compliance/ non-adherence and drug-drug interactions, as well as more chances of adverse drug events [47]. The present study, however, had $20(16.0 \%)$ patients who took more than two drugs to attain HbA1c target of $<7 \%$. These patients would need to be followed to see that they adhere to therapy. 
The small study population size was the major limitation of the study. Moreover, as per ADA, in addition to HbA1c, other parameters such as fasting blood glucose, low density lipoprotein- cholesterol (LDL-C), hypertension, proteinuria, etc. should also be assessed. However, the present study has not assessed these parameters.

\section{Conclusion}

Overall, 86 (68.8\%) patients were able to achieve HbA1c targets using mono or multiple OHAs, representing that the majority of patients with T2DM can be managed using OHAs. Among OHAs, metformin, alone, was received by maximum number of patients, i.e., $40(32.0 \%)$ followed by DPP4 monotherapy $(n=18 ; 14.4 \%)$. The most commonly used combinations were metformin+GLP1 ( $n=11$; $8.8 \%$ ), followed by combination of DPP4 and SGLT2 inhibitors ( $\mathrm{n}=10 ; 8 \%)$. Only 20 (16\%) patients received more than two drugs to attain $\mathrm{HbA1c}$ targets. However, the number of patients achieving a level of HbA1c less than $7 \%(n=125 ; 53.4 \%)$ is still below the target level in many patients.

The response of an individual to each drug is different and it depends upon the patient's ethnicity and characteristics. The choice of drug also varies due to patient preferences, characteristics, associated comorbidities as well as drug characteristics. Therefore, it is essential to prescribe a regimen keeping everything into consideration. Further studies should be carried out to assess if the patients are prescribed antihyperglycemic agents keeping this in mind. In the present study, glycemic control of $\mathrm{HbA1c}<7$ was achieved by much higher proportion of patients than previously reported from this region. Therefore, larger studies in UAE are required to assess if $\mathrm{HbA1c}$ target as per ADA is being achieved in higher proportion of patients as shown in this study. Measures being taken to improve glycemic control should also be assessed.

\section{Acknowledgement}

The authors are thankful to Turacoz Healthcare Solutions (www.turacoz.com) for the writing support.

\section{Conflict of interest}

No conflict of interest.

\section{References}

1. WHO (2019) Diabetes 2019.

2. IDF (2017)

3. Unnikrishnan R, Pradeepa R, Joshi SR, Mohan V (2017) Type 2 diabetes: demystifying the global epidemic. Diabetes 66(6): 1432-1442.

4. Singapore Cancer Network Lung Cancer W (2015) Singapore Cancer Network (SCAN) Guidelines for the Use of Systemic Therapy in Advanced Non-Small Cell Lung Cancer. Ann Acad Med Singapore 44(10): 449-462.

5. Meo SA (2016) Prevalence and future prediction of type 2 diabetes mellitus in the Kingdom of Saudi Arabia: A systematic review of published studies. J Pak Med Assoc 66(6): 722-725.

6. Florkowski C (2013)HbA1c as a Diagnostic Test for Diabetes Mellitus Reviewing the Evidence. Clin Biochem Rev 34(2): 75-83.
7. Association AD (2018) 6. Glycemic targets: standards of medical care in diabetes 2018. Diabetes Care 41(Supplement 1): S55-S64.

8. Duckworth W, Abraira C, Moritz T, Reda D, Emanuele N, et al. (2009) Glucose control and vascular complications in veterans with type 2 diabetes. N Engl J Med 360(2): 129-139.

9. Group AC, Patel A, MacMahon S, Chalmers J, Neal B, et al. (2008) Intensive blood glucose control and vascular outcomes in patients with type 2 diabetes. N Engl J Med 358(24): 2560-2572.

10. Ohkubo Y, Kishikawa H, Araki E, Miyata T, Isami S, et al. (1995) Intensive insulin therapy prevents the progression of diabetic microvascular complications in Japanese patients with non-insulin-dependent diabetes mellitus: a randomized prospective 6-year study. Diabetes Res Clin Pract 28(2): 103-117.

11. UKPDS (1998) Intensive blood-glucose control with sulphonylureas or insulin compared with conventional treatment and risk of complications in patients with type 2 diabetes (UKPDS 33). UK Prospective Diabetes Study (UKPDS) Group. Lancet 352(9131): 837-853.

12. UKPDS (1998) Effect of intensive blood-glucose control with metformin on complications in overweight patients with type 2 diabetes (UKPDS 34). UK Prospective Diabetes Study (UKPDS) Group. Lancet 352(9131): 854-865.

13. Holman RR, Paul SK, Bethel MA, Matthews DR, Neil HA (2008) 10-year follow-up of intensive glucose control in type 2 diabetes. $\mathrm{N}$ Engl J Med 359(15): 1577-89.

14. Abuyassin B, Laher I (2016) Diabetes epidemic sweeping the Arab world. World J Diabetes 7(8): 165-174.

15. Al Rifai RH, Aziz F (2018) Prevalence of type 2 diabetes, prediabetes, and gestational diabetes mellitus in women of childbearing age in Middle East and North Africa, 2000-2017: protocol for two systematic reviews and meta-analyses. Syst Rev 7(1): 96.

16. Majeed A, El Sayed AA, Khoja T, Alshamsan R, Millett C, et al. (2014) Diabetes in the Middle-East and North Africa: an update. Diabetes Res Clin Pract 103(2): 218-222.

17. Yudkin JS (2016) Prediabetes: are there problems with this label? Yes, the label creates further problems! Diabetes Care 39(8):1468-71.

18. Ogurtsova K, Da Rocha Fernandes JD, Huang Y, Linnenkamp U, Guariguata L, et al. (2017)IDF Diabetes Atlas: Global estimates for the prevalence of diabetes for 2015 and 2040. Diabetes Res Clin Pract 128: 40-50.

19. Shaw JE, Sicree RA, Zimmet PZ (2010) Global estimates of the prevalence of diabetes for 2010 and 2030. Diabetes Res Clin Pract 87(1): 4-14.

20. Al Khalaf MM, Eid MM, Najjar HA, Alhajry KM, Doi SA, et al. (2010) Screening for diabetes in Kuwait and evaluation of risk scores. East Mediterr Health J 16(7): 725-731.

21. Ng SW, Zaghloul S, Ali HI, Harrison G, Popkin BM (2011) The prevalence and trends of overweight, obesity and nutrition-related noncommunicable diseases in the Arabian Gulf States. Obes Rev 12(1): 1-13.

22. Al Nozha MM, AlMaatouq MA, Al-Mazrou YY, Al-Harthi SS, et al. (2004) Diabetes mellitus in Saudi Arabia. Saudi Med J 25(11): 1603-1610.

23. Nathan DM, Buse JB, Davidson MB, Ferrannini E, Holman RR, et al. (2009) Medical management of hyperglycemia in type 2 diabetes: a consensus algorithm for the initiation and adjustment of therapy: a consensus statement of the American Diabetes Association and the European Association for the Study of Diabetes. Diabetes Care 32(1): 193-203.

24. ADA (2019) Tight diabetes control 2019.

25. Sherwani SI, Khan HA, Ekhzaimy A, Masood A, Sakharkar MK (2016) Significance of HbA1c Test in Diagnosis and Prognosis of Diabetic Patients. Biomark Insights 11: 95-104.

26. Qaseem A, Wilt TJ, Kansagara D, Horwitch C, Barry MJ, et al.(2018) Hemoglobin A1c Targets for Glycemic Control With Pharmacologic Therapy for Nonpregnant Adults With Type 2 Diabetes Mellitus: A 
Guidance Statement Update From the American College of Physicians Ann Intern Med 168(8): 569-576.

27. ADA(2019) Deeply Concernedby New ACP Recommendations for Diabetes Management.

28. AlMazroa M (2018) Cost of Diabetes in Saudi Arabia. Iproceedings 4(1): e10566.

29. Mokdad AH, Tuffaha M, Hanlon M, El Bcheraoui C, Daoud F, et al. (2015) Cost of diabetes in the Kingdom of Saudi Arabia. J Diabetes Metab 6(575): 2 .

30. Albache N, Al Ali R, Rastam S, Fouad FM, Mzayek F, et al. (2010) Epidemiology of Type 2 diabetes mellitus in Aleppo, Syria. J Diabetes 2(2): 85-91.

31. Saadi H, Carruthers SG, Nagelkerke N, Al-Maskari F, Afandi B, et al. (2007) Prevalence of diabetes mellitus and its complications in a populationbased sample in Al Ain, United Arab Emirates. Diabetes Res Clin Pract 78(3): 369-377.

32. AlElq AH (2009) Current practice in the management of patients with type 2 diabetes mellitus in Saudi Arabia. Saudi Med J 30(12): 1551-1556.

33. Kharal M, AlHajjaj A, Al-Ammri M, Al-Mardawi G, Tamim HM, et al. (2010)Meeting the American Diabetic Association standards of diabetic care. Saudi J Kidney Dis Transpl 21(4): 678-685.

34. AlKhaldi Y (2014) Quality of diabetic care in family practice centre, Aseer Region, Saudi Arabia. J Health Spec 2(3): 109.

35. Alramadan MJ, Magliano DJ, Almigbal TH, Batais MA, Afroz A, et al. (2018) Glycaemic control for people with type 2 diabetes in Saudi Arabia - an urgent need for a review of management plan. BMC Endocr Disord 18(1): 62.

36. Khattab M, Swidan A, Farghaly M, Swidan H, Ashtar M, et al. (2007) Quality improvement programme for diabetes care in family practice settings in Dubai 2007.

37. Cavaiola TS, Pettus JH (2017) Management of type 2 diabetes: selecting amongst available pharmacological agents 2017

\section{ISSN: 2574-1241}

DOI: 10.26717/BJSTR.2019.21.003578

Omar Dhaimat. Biomed J Sci \& Tech Res

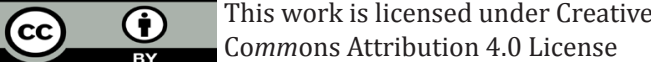

Submission Link: https://biomedres.us/submit-manuscript.php
38. Cahn A, Cefalu WT (2016) Clinical considerations for use of initial combination therapy in type 2 diabetes. Diabetes Care 39(Supplement 2): S137-45.

39. Esposito K, Chiodini P, Bellastella G, Maiorino M, Giugliano DJD (2012) Obesity, Metabolism. Proportion of patients at HbA1c target< $7 \%$ with eight classes of antidiabetic drugs in type 2 diabetes: systematic review of 218 randomized controlled trials with 78945 patients 14(3): 228-33.

40. Blonde L, Raccah D, Lew E, Meyers J, Nikonova E, et al. (2018) Treatment Intensification in Type 2 Diabetes: A Real-World Study of 2-OAD Regimens, GLP-1 RAs, or Basal Insulin. Diabetes Ther 9(3): 1169-1184.

41. Ponssen HH, Elte JW, Lehert P, Schouten JP, Bets D (2000) Combined metformin and insulin therapy for patients with type 2 diabetes mellitus. Clin Ther 22(6): 709-718.

42. Wulffelé MG, Kooy A, Lehert P, Bets D, Ogterop JC, et al. (2002) Combination of insulin and metformin in the treatment of type 2 diabetes. Diabetes care 25(12): 2133-2140.

43. Hermann LS (1998) Combination therapy with insulin and metformin Endocr Pract 4(6): 404-412.

44. Pratley RE, Nauck M, Bailey T, Montanya E, Cuddihy R, et al. (2010) Liraglutide versus sitagliptin for patients with type 2 diabetes who did not have adequate glycaemic control with metformin: a 26-week, randomised, parallel-group, open-label trial. Lancet 375(9724): 14471456.

45. Min SH, Yoon JH, Moon SJ, Hahn S, Cho YM (2018) Combination of sodium-glucose cotransporter 2 inhibitor and dipeptidyl peptidase-4 inhibitor in type 2 diabetes: a systematic review with meta-analysis. Sci Rep 8(1): 4466.

46. Downes MJ, Bettington EK, Gunton JE, Turkstra E (2015) Triple therapy in type 2 diabetes; a systematic review and network meta-analysis. Peer J 3: e1461.

47. Peron EP, Ogbonna KC, Donohoe KL (2015) Antidiabetic medications and polypharmacy. Clin Geriatr Med 31(1): 17-27.

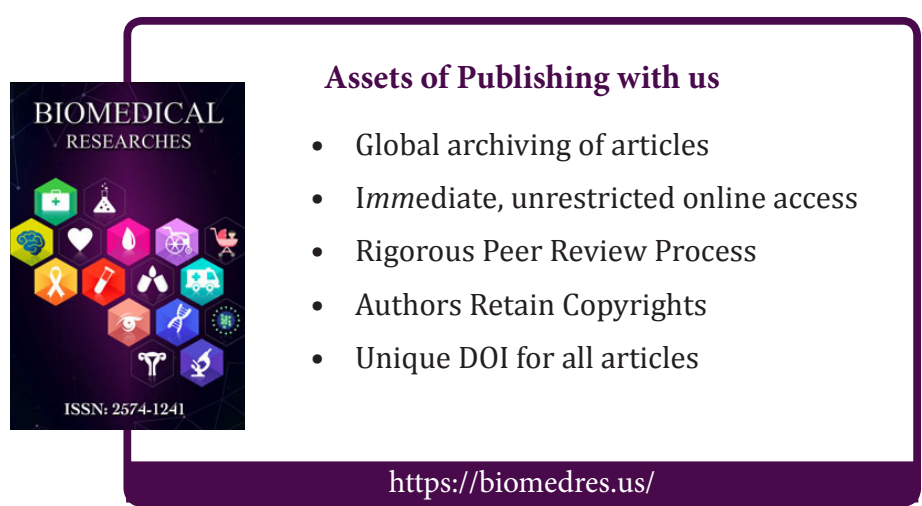

